\title{
Global distribution of the lithosphere-asthenosphere boundary: a new look
}

\author{
V. M. Hamza and F. P. Vieira \\ Observatório Nacional, Rua Genral José Cristino, 77, Rio de Janeiro, Brazil \\ Correspondence to: V. M. Hamza (hamza@on.br) \\ Received: 11 January 2012 - Published in Solid Earth Discuss.: 8 February 2012 \\ Revised: 4 July 2012 - Accepted: 9 July 2012 - Published: 8 August 2012
}

\begin{abstract}
New global maps of the depth to the boundary between the lithosphere and the asthenosphere are presented. The maps are based on updated global databases for heat flow and crustal structure. For continental regions the estimates of lithospheric thickness are based on determinations of subcrustal heat flow, after corrections for contributions of radiogenic heat in crustal layers. For oceanic regions the estimates of lithospheric thickness are based on the newly proposed finite half-space (FHS) model. Unlike the half-space cooling (HSC) and the plate models the FHS model takes into account effects of buffered solidification at the lower boundary of the lithosphere and assumes that the vertical domain for downward growth of the boundary layer have an asymptotic limit. Results of numerical simulations reveal that theoretical values derived from the FHS model provide vastly improved fits to observational data for heat flow and bathymetry than can be achieved with HSC and plate models. Also, the data fits are valid for the entire age range of the oceanic lithosphere. Hence estimates of depths to lithosphere- asthenosphere boundary (LAB) based on the FHS model are believed to provide more reliable estimates than those reported in previous thermal models.

The global maps of depths to LAB derived in the present work reveal several features in regional variations of lithosphere thicknesses that have not been identified in earlier studies. For example, regions of ocean floor with ages less than $55 \mathrm{Ma}$ are characterized by relatively rapid thickening of the lithosphere. Also there is better resolution in mapping the transition from oceanic to continental lithosphere, as most of the latter ones are characterized by lithospheric thickness greater than $150 \mathrm{~km}$. As expected the plate spreading centers in oceanic regions as well as areas of recent magmatic activity in continental regions are characterized by rel-
\end{abstract}

atively thin lithosphere, with LAB depths of less than $50 \mathrm{~km}$. On the other hand, the areas of continental collisions and Precambrian cratonic blocks are found to have lithosphere thicknesses in excess of $250 \mathrm{~km}$. Regional variations of lithosphere thickness in the interiors of continents are found to depend on the magnitude of subcrustal heat flux as well as the tectonic age of crustal blocks.

\section{Introduction}

The concepts of lithosphere and asthenosphere are fundamental components of plate tectonic theory, according to which the lithosphere-asthenosphere boundary (LAB) separates the upper rigid part from the underlying upper mantle in both oceanic and continental regions. It is often considered as a first-order structural discontinuity that allows for differential motion between tectonic plates and the underlying mantle. Mapping the depth of lithosphere-asthenosphere boundary is important, since it is an essential constraint in models of formation and evolution of oceanic and continental regions. Detailed models of mantle convection depend on accurate knowledge of the depth variations of the lithosphere-asthenosphere boundary. In oceanic regions large scale variations in heat flow and bathymetry has often been interpreted as indicative of systematic increase in the depth of lithosphere-asthenosphere boundary with distance from the spreading centers (see for example: Parsons and Sclater, 1977). In continental areas thick lithospheric roots appear to exhibit large variations in thickness (Artemieva and Mooney, 2002; Babuška and Plomerová, 2006; Plomerová et al, 2008; Eaton et al., 2009) and are likely to represent regions where the plates are strongly coupled to mantle flow (Conrad and 
Lithgow-Bertelloni, 2006). There are also evidences indicating that the lithosphere is thickest, strongest and most refractory within the cratonic nuclei of continents (e.g., Jordan, 1981; Plomerová et al, 2006; Plomerová and Babuška, 2010).

Recent advances in seismological data analysis and interpretation have allowed considerable improvements in deriving LAB models of quite high quality and resolution (Babuška and Plomerová, 2006; Plomerová et al, 2006; Plomerová and Babuška, 2010). The limitation of seismological techniques is apparently limited to cases where differential motion between lithosphere and asthenosphere is accommodated by passive deformation. Global observations of the Earth's gravity field show that the lithosphere is approximately in large-scale isostatic equilibrium (Sclater et al., 1975; Shapiro et al., 1999) and hence long-wavelength gravity inversion turns out to be an ineffective mapping tool. Results of magnetotelluric observations have, for many decades, been interpreted as indicative of an electrically conductive layer at depths beneath the continents, consistent with seismic low velocity zones. Indirect methods have also been used in investigating the petrologic and geochemical characteristics of the LAB and adjacent regions. Nevertheless, there are considerable shortcomings in the methods employed in geologic studies and the results are plagued with large uncertainties. On the other hand, results of geothermal methods, based on observational data and thermal models, allow determination of temperatures in the lithosphere and this information may easily be employed in mapping LAB with relatively improved degree of reliability.

The purpose of this paper is to provide a new look into the regional variations in the depths of LAB based primarily on near surface heat flow data and on the knowledge of the thermal structure of the lithosphere. The procedure employed allows determination of the thickness of the layer in which temperatures lie below the mantle adiabat and where the heat transport is mainly conductive. This part of the lithosphere is usually identified as the thermal boundary layer (TBL) that overlie the mantle convection system. We also examine the differences in the processes that determine regional variations in the thickness of the TBL in oceanic and continental regions.

\section{Heat flow data and global heat flow maps}

The determination of depth of LAB is a task that requires use of thermal models which provide physically reasonable fits to observational data sets on heat flow and basal temperatures and are at the same time compatible with the prevailing knowledge of crustal structure (thickness, seismic velocity, radiogenic heat production and physical properties of crustal layers as well as their geological characteristics). We present brief descriptions of the heat flow maps derived from the updated world heat flow data set, as an important prelude to the
Table 1. Summary of updated global heat flow data (Derived from Vieira and Hamza, 2010).

\begin{tabular}{l|l|c|c}
\hline Regions & & Number of Data & $\%$ \\
\hline \multirow{5}{*}{ Continental } & Africa & 859 & 2.1 \\
& Asia & 4071 & 9.8 \\
& Europe & 5967 & 14.4 \\
& Oceania & 697 & 1.7 \\
& North America & 5008 & 12.1 \\
& South America & 3173 & 7.7 \\
& Total Continents & 19775 & 47.8 \\
\hline \multirow{5}{*}{ Oceanic } & Atlantic & 2400 & 5.9 \\
& Indian & 2066 & 4.7 \\
& Pacific & 10930 & 27.1 \\
& Mediterranean & 1682 & 4.2 \\
& Inland seas and Gulfs & 4533 & 11.2 \\
& Total Oceans & 21611 & 52.2 \\
\hline \multirow{6}{*}{ Global } & Total & 41386 & 100 \\
\hline
\end{tabular}

discussion of thermal models relevant for determination of LAB depths in oceanic and continental regions.

\subsection{Heat flow data set}

The observational heat flow data set employed in the present work is derived from an updated compilation carried out recently by Vieira and Hamza (2010). It makes extensive use of data sets reported in earlier compilations of Pollack et al. (1993), Hamza et al. (2008a), and Davies and Davies (2010), but also includes updated data sets for the South American continent. At present, the global data set consists of a total 41386 heat flow measurements, of which 19775 are in continental regions and 21611 in oceanic regions. A summary of this updated data set for continental and oceanic regions is provided in Table 1 and its global distribution illustrated in the map of Fig. 1.

The age values are derived from the geologic maps published by Mooney et al. (1998) for continental areas and Muller et al. (2008) for oceanic areas. Modern geographic information science (GIS) techniques have been employed in deriving polygons that delimit subunits of geologic and structural provinces and the tectonic age pattern. These are superimposed on the reference grid system of $1^{\circ} \times 1^{\circ}$ area elements, which allowed determinations of the area segments of the geologic subunits and the values of mean heat loss for the corresponding "tectonic polygons".

This data set was employed in calculating mean heat flow for a regular grid system composed of $1^{\circ} \times 1^{\circ}$ area elements. Such a grid system has a total of 63800 cells, of which 22380 are in continental areas and 42420 are in oceanic areas. A detailed examination of the data set reveal that heat flow measurements have been carried out in areas corresponding to nearly $70 \%$ of the grid cells. The remaining $30 \%$ of the grid cells are devoid of observational data. Such 


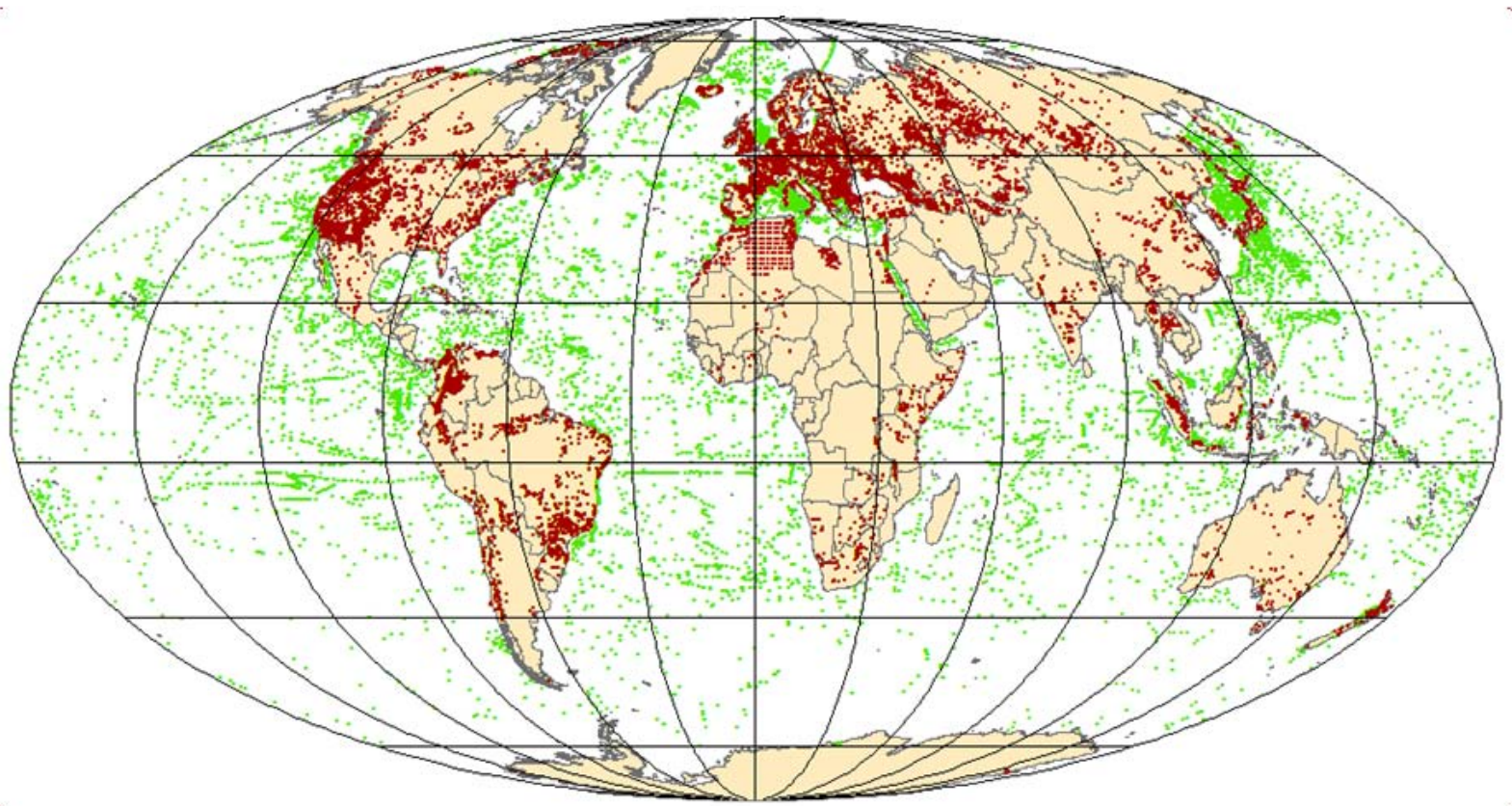

Fig. 1. Geographic distribution of heat flow measurements, as per the updated data base reported by Vieira and Hamza (2010).

inhomogeneous distributions of data are known to lead to problems in deriving global maps. One of the convenient techniques employed in overcoming such problems in uneven data distribution is to make use of estimated values that are representative of the tectonic context. Following the practice adopted in the earlier works (for example Chapman and Pollack, 1975; Pollack et al., 1993), we also make use of the empirical predictor based on the well known heat flow-age relation in estimating values for cells devoid of experimental data. The heat flow values assigned for age provinces are based on a modified version of the results reported by Hamza (1967), Polyak and Smirnov (1968) and Hamza and Verma (1969). The modifications introduced take into consideration advances obtained in determining the functional form of the relation between heat flow and age in North America, Australia, Europe, South America, Africa and Asia. The only exception is the region of Antarctica for which a constant heat flow value of $45 \mathrm{~mW} \mathrm{~m}^{-2}$ has been assigned.

\subsection{Global heat flow maps}

In calculating representative mean values of heat flow for intersecting "tectonic polygons" we have assigned equal weights to both oceanic and continental data sets. Another outstanding feature of the present work concerns the use of heat flow data sets for ocean crust with ages less than $55 \mathrm{Ma}$. We have refrained from the practice (employed in some earlier works) of using theoretical heat flow values, derived from half-space cooling models, as substitutes for experimental data. The reason is the controversy concerning the hypothesis of regional scale hydrothermal circulation in young ocean crust. As pointed out by Hofmeister and Criss (2005) and Hamza et al. (2008), this hypothesis, which implies down flow of cold water into hot crust and up flow of hot water from cold crust, contradicts the basic principles of thermal convection in geologic media. In addition, the half- space cooling models assume conductive heat loss from stagnant fluid bodies, a process unlikely to be representative of conditions in which lateral mass movements take place (Hamza et al., 2010).

The global heat flow map, derived from the observational data set and estimated values, is presented in Fig. 2. It reveals several features related to regional variations in both continental and oceanic regions. It is now possible to identify, with much better resolution, thermal anomalies associated with mid ocean ridges, areas of magmatic activity associated with subduction processes in back-arc regions and hot-spot localities in both oceanic and continental regions. Also, the map allows identification of areas of relatively low heat flow in the interiors of continents as distinct from areas of normal heat flow in continental platform areas and ocean basins.

\subsection{Thermal models of the oceanic lithosphere: implications for LAB depths}

The difficulties in previous attempts at mapping LAB depths in oceanic regions are in part related to fundamental problems in the use of thermal models of the lithosphere. For example, the so-called half-space cooling (Turcotte and Oxburgh, 1967) and plate models (McKenzie, 1967) fail to provide satisfactory accounts of observational heat flow and 


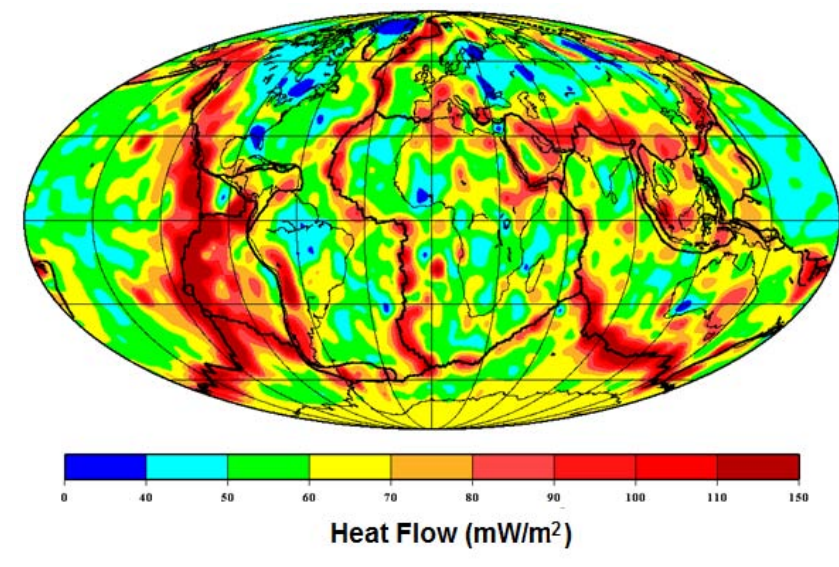

Fig. 2. Global heat flow map derived from observational data (Vieira and Hamza, 2010) and estimated values based on heat flow-age relation (Hamza, 1967; Polyak and Smirnov, 1968; Hamza and Verma, 1969).

bathymetry data sets for the young ocean floor. This is also true of the hybrid thermal model, commonly referred to as the global depth-heat flow (GDH) model (Stein and Stein, 1992). We examine here briefly the main limitations of the half-space cooling, plate and global depth-heat flow models and point out how these difficulties has been overcome in the newly proposed finite half-space (FHS) model (Cardoso and Hamza, 2011).

\subsection{Half-space cooling (HSC) model}

In the half-space cooling (HSC) model, the lithosphere is considered as the boundary layer of mantle convection cells. The lithosphere grows in thickness continuously as it moves away from the up-welling limb of the mantle convection system. The cooling process of the lithosphere is assumed to be conductive and one-dimensional. In other words, lateral variations in temperatures of the underlying asthenosphere are not permitted. Analytical expressions for variation of temperature $(T)$ with time $(t)$ and depth $(z)$ in such a boundary layer may be obtained as solution to the one-dimensional heat conduction equation:

$$
\frac{\partial T}{\partial t}=\kappa \frac{\partial^{2} T}{\partial z^{2}}
$$

where $\kappa$ is the thermal diffusivity. If the wavelength of the problem addressed in Eq. (1) is assumed to be large $(z \rightarrow \infty)$ its solution may be expressed in terms of the error function (erf) as (Carslaw and Jaeger, 1959)

$$
\frac{T(z, t)-T_{0}}{\left(T_{m}-T_{0}\right)}=\operatorname{erf}\left(\frac{z}{2 \sqrt{\kappa t}}\right) \text {. }
$$

The fit of HSC model curve (derived from Eq. 2) to observational heat flow data is known to be poor. It overestimates heat flow in ocean crust with ages less than $60 \mathrm{Ma}$ and underestimates heat flow for crust with ages greater than $100 \mathrm{Ma}$. Such difficulties arise from the main drawback of the halfspace cooling model (HSC), which is the implicit assumption that the wavelength of the problem domain is unbounded. This assumption implies that the thickness of the material undergoing solidification beneath the boundary layer is large compared to the stable thickness of the lithosphere at large distances from the ridge axis. As pointed out by Hamza et al. (2010), this condition cannot be considered as satisfactory for the physical domain of the problem under consideration, since the upwelling material beneath the ridge axis has a finite width. Since this is the same magmatic material that moves laterally away from the ridge zone, its thickness has to be finite.

\subsection{Plate and global depth-heat flow (GDH) models}

The plate model proposed by McKenzie (1967) is known to provide a better fit to heat flow data from ocean crust with ages greater than $100 \mathrm{Ma}$. Nevertheless, it also overestimates heat flow for ocean crust with ages less than $55 \mathrm{Ma}$. In an attempt to overcome such difficulties, Stein and Stein (1992) proposed a hybrid version, referred to also as the global depth-heat flow (GDH) Reference model. The GDH model is successful in providing a satisfactory explanation for regional variations in bathymetry but fail in accounting for the low values of heat flow in ocean crust with ages less than $55 \mathrm{Ma}$. The problem eventually came to be known as the oceanic heat flow paradox. Stein and Stein (1992) and Pollack et al. (1993) invoked the hypothesis of convective heat transport by regional scale hydrothermal circulation in ocean crust as a possible mechanism responsible for the appearance of this paradox. Nevertheless, the proposed scheme of water circulation is based on the assumption of down flow of cold water into hot crust and up flow of hot water from cold crust.

Hofmeister and Criss (2005) and Hamza et al. (2006) have drawn attention to fundamental inconsistencies in the hypothesis of regional scale hydrothermal circulation in ocean crust. In addition, Hamza et al. (2008b) pointed out that the GDH model implies large scale discontinuities in the deep thermal fields of the oceanic lithosphere. More recently, Cardoso and Hamza (2011) argued that the physical basis of the HSC, plate and GDH models are deficient in the sense that these do not take into account explicitly the effects of latent heat and the process of buffered solidification at the asthenosphere-lithosphere boundary. In view of such difficulties estimates of depths to LAB calculated on the basis of HSC, GDH and plate models cannot be considered reliable.

\subsection{Finite half-space (FHS) model}

It is clear that we need to look for a model that accounts for the effects of latent heat of magma accretion and the process of buffered solidification at the base of the lithosphere. 
Hamza et al. (2010) presented a model that takes into consideration the thermal consequences of variable rates of magma accretion at the lower boundary of the lithosphere. According to this model (designated VBA), the variability in the rate of magma accretion at the base of the lithosphere has a direct influence on surface heat flux and bathymetry. More importantly, VBA model has been found to be capable of accounting for the main features in observational data sets of heat flow and bathymetry, without the need to invoke the hypothesis of regional scale hydrothermal circulation in ocean crust. Nevertheless, VBA model does not address explicitly the thermal effects of latent heat at the lithosphere- asthenosphere boundary.

Cardoso and Hamza (2011) have been successful in the formulation of a new model that incorporates the effects of latent heat and buffered solidification, and at the same time provide a satisfactory solution for large scale variations of bathymetry and heat flux in the ocean floor. Designated as the finite half-space model - FHS, it introduces the assumption that the wavelength of the solution of the relevant heat conduction equation is related to the thickness of the stable lithosphere at large distances from the ridge axis. A major consequence of this assumption is that it imposes an asymptotic limit for the vertical growth of the lithosphere at the expense of the asthenosphere. Further, the FHS model assumes that the solidification process is buffered, taking place between the liquidus and solidus temperatures $\left(T_{\mathrm{L}}\right.$ and $T_{\mathrm{S}}$ respectively) of asthenospheric material at the base of the lithosphere. Under these conditions the solution for the temperature $(T)$ at depth $(z)$ in the oceanic lithosphere of age $(t)$ and of basal temperature $\left(T_{\mathrm{m}}\right)$ is (Cardoso and Hamza, 2011)

$T(z, t)=T_{0}+\left(T_{\mathrm{m}}-T_{0}\right) \frac{\operatorname{erf}\left(z / 2 \sqrt{\kappa_{\bmod } t}\right)}{\operatorname{erf}\left(a / 2 \sqrt{\kappa_{\bmod } t}\right)}$

where $a$ is the asymptotic value for the thickness of the lithosphere in stable ocean basins and $k_{\bmod }$ is the modified thermal diffusivity, that takes into account the role of latent heat:

$\kappa_{\text {mod }}=\frac{\lambda}{\rho_{\text {Lit }} C_{p}-\rho_{\text {Ast }} L(d V / d T)}$.

In Eq. (4) $\lambda$ is the thermal conductivity of the lithosphere, $\rho_{\text {Ast }}$ and $\rho_{\text {Lit }}$ the densities of asthenosphere and lithosphere respectively and $L$ the latent heat of solidification of the asthenospheric material at the base of the lithosphere. The expression $d V / d T$ in Eq. (4) is the volumetric proportion of the solidification reaction assumed to be buffered between the liquidus $\left(T_{\mathrm{L}}\right)$ and solidus $\left(T_{\mathrm{S}}\right)$ temperatures. For unit change in temperature the variation of $V$ is defined as

$V(T)=\frac{\left(e^{b T}-e^{b T_{S}}\right)}{\left(e^{b T_{L}}-e^{b T_{S}}\right)}$.
In Eq. (5) $b$ is a constant that determines partitioning between the liquid and solid fractions in the buffered solidification process. Note that $V$ in Eq. (5) has the unit of percent and not cubic meters.

A careful examination of the Eq. (3) reveals that the solution provided by the FHS model represents in fact the general case for thermal models of the lithosphere. In fact, it is possible to demonstrate that the solutions derived in the HSC and plate models represent particular end member cases of the FHS model. Consider for example the solution for small values of time $(t)$ and values of depth $(z)$ much less than the thickness of the stable lithosphere $(a)$. In this limiting case, the right hand side of Eq. (3) is nearly identical to that of the fundamental solution for temperature in the HSC model, whereby the only difference is the modified form of thermal diffusivity. On the other hand, for depth values $(z)$ nearly equal to the stable thickness of the lithosphere $(a)$, the right hand side of Eq. (1) approaches unity, which is the condition employed in the plate model of McKenzie (1967). In other words, the FHS model behavior is similar to that of the HSC model for small times but similar to that of the plate model for large times.

Cardoso and Hamza (2011) derived relations for surface heat flux and bathymetry within the framework of the FHS model. These relations are however based on the assumption of constant thermal properties for the medium. Recently, Whittington et al. (2009) and Nebelek et al. (2010) have reported non linear variations in thermal diffusivity relevant to temperature distributions at depth levels of the lower lithosphere. At shallow depth levels of the lithosphere the phonon component of thermal conductivity decreases with temperature. But at intermediate depths, phonon and radiative contributions are opposite in sign and overall value of thermal diffusivity remains nearly the same. At larger depths of the mantle, lithosphere diffusivity variations arising from radiative heat transfer are expected to become dominant. This problem is likely to have only a limited impact on the final estimates of temperatures at LAB as most of the temperature variations (and consequently variations in thermal diffusivity) occur in the upper parts of the lithosphere. Mantle lithosphere in oceanic regions is nearly isothermal and errors associated with variations in diffusivity are likely to appear as relatively small systematic errors in the depth to LAB.

For the case of constant thermal diffusivity, the equation for surface heat flux in FHS model may be written as

$q(t)_{z=0}=\lambda \frac{\left(T_{m}-T_{0}\right)}{\sqrt{\left(\pi \kappa_{\bmod t)}\right.}} \frac{1}{\operatorname{erf}(a / 2 \sqrt{\kappa \bmod t})}$. 
The relation for bathymetry in FHS model may be derived following the isostatic compensation scheme discussed in earlier studies (e.g. McKenzie, 1967; Sclater and Francheteau, 1970; Parsons and Sclater, 1977):

$$
\begin{gathered}
e(t)=d_{r}+\frac{\alpha a T_{\mathrm{m}} \rho_{a}}{\sqrt{\pi}\left(\rho_{a}-\rho_{w}\right)} \\
{\left[\frac{\left.1-e^{-\left(a / 2 \sqrt{\kappa_{\bmod } t}\right.}\right)^{2}}{\left(a / 2 \sqrt{\kappa_{\bmod } t}\right) \operatorname{erf}\left(a / 2 \sqrt{\kappa_{\bmod } t}\right.}\right]}
\end{gathered}
$$

The fits to the observational data sets for heat flow and ocean floor bathymetry, on the basis of Eqs. (6) and (7), are presented respectively in the upper and lower panels of Fig. 3. Also illustrated in this figure are the fits provided by the GDH model of Stein and Stein (1992). It is fairly simple to note that the fit of FHS model to observational heat flow data is far superior to that which can be produced by HSC, GDH and plate models. More importantly, the fits obtained are valid for the entire age range of the oceanic lithosphere, there being no need to invoke the hypothesis of regional scale hydrothermal circulation in ocean crust. In the case of bathymetry, GDH and FHS model fits are almost identical. Nevertheless, the GDH model fit requires the hybrid scheme, with changes in model parameters for bathymetry calculations at the age value of $25 \mathrm{Ma}$ for the ocean crust.

\subsection{Lithosphere-asthenosphere boundary (LAB) depths}

We now examine the fit of the finite half-space (FHS) model to oceanic heat flow data as part of the attempt to map regional variations in the depth of lithosphere-asthenosphere boundary (LAB) in oceanic regions. In this task it is important to set a value for basal temperature that is compatible with results of petrology and thermal models of the lithosphere. However, there is no universal agreement as to the representative value of the basal temperature to be used in model studies of the lithosphere. According to Green et al. (2001) primary magmas in the Hawaiian region have an average temperature of $1365^{\circ} \mathrm{C}$, but presence of even small amounts of volatiles can lead to temperatures as low as $1000^{\circ} \mathrm{C}$. McKenzie and Bickle (1988) infer that asthenosphere have a potential temperature of $1280^{\circ} \mathrm{C}$. McNutt (1990) and Jaupart and Mareschal (1999) assume that the thickness of the mechanical lithosphere is proportional to the thickness of the conductive thermal boundary layer and defines the base of the thermal lithosphere as the intersection of the geotherm with the mantle abiabat of $1300^{\circ} \mathrm{C}$. Parsons and Sclater (1977) and Sclater et al. (1980) used observational data on bathymetry of various oceans to estimate the best fitting value of $1333^{\circ} \mathrm{C}$ for the basal temperature. The same approach was used by Stein and Stein (1992), who argued that a basal temperature of $1450^{\circ} \mathrm{C}$ at a depth of $95 \mathrm{~km}$ fit the data better than the values estimated by Parsons and Sclater (1977). For purposes of the present work, the basal temperature of lithosphere is assumed to fall in the interval of 1250 to $1350^{\circ} \mathrm{C}$. The time variation of LAB for oceanic lithosphere, derived from Eq. (3), is illustrated in Fig. 4.

Also illustrated in Fig. 4 is a comparison of the thickness variations of the lithosphere according to the finite half-space (FHS) and half-space cooling (HSC) models. The dashed curves in this figure indicate depths of lithosphere-asthenosphere boundary (LAB) derived from the HSC model, which plunge to values of more than $90 \mathrm{~km}$, for ages greater than $55 \mathrm{Ma}$. On the other hand, the FHS model depths to LAB approach asymptotic values of no more than $90 \mathrm{~km}$ for age values in excess of $80 \mathrm{Ma}$. This asymptotic limit is compatible with the thickness of the stable lithosphere in ocean basins. Another remarkable feature of the finite half-space (FHS) model is that regions of ocean floor with ages less than $25 \mathrm{Ma}$ are characterized by relatively rapid thickening of the lithosphere, when compared with the half-space cooling (HSC) model values. This is also a consequence of the FHS model, which imposes a rapid decrease in magma accretion rates at the base of the lithosphere, as it moves away from the ridge axis. The most important conclusion is that the depth to lithosphere-asthenosphere boundary (LAB) of oceanic lithosphere is controlled by processes of magmatic accretion and solidification occurring at its lower boundary. As pointed out in the next section this is quite different from that of the continental lithosphere.

\section{Lithosphere-asthenosphere boundary (LAB) in continental regions}

The thermal state of the continental lithosphere has been addressed in numerous publications (e.g. Jordan, 1981; Plomerová and Babuška, 2008). Most of the individual studies are focussed on Precambrian cratonic areas in South America, South Africa, the Baltic Shield, the Indian Shield, Australia, and North America. There are relatively few publications on the thermal state of the lithosphere in younger continental areas, reactivated during Cenozoic, Mesozoic and Paleozoic times. Comparison of results reported in such studies is a difficult task as there are no consistent practices in setting thermal parameter values employed in model simulations.

\subsection{Crustal model}

In an attempt to minimize problems of this type we have made use of, in the present work, global compilations of data on thickness, density and seismic velocity of the crustal layers reported in the works of Mooney et al. (1998) and Bassin et al. (2000). In these data sets the crust is assumed to be composed of five sequential layers, classified as soft (unconsolidated) sediments, hard (lithified) sediments, upper crust, middle crust and lower crust. Soft sedimentary layers of significant thickness are generally present in areas of active deposition of sediments (such as continental margins). 

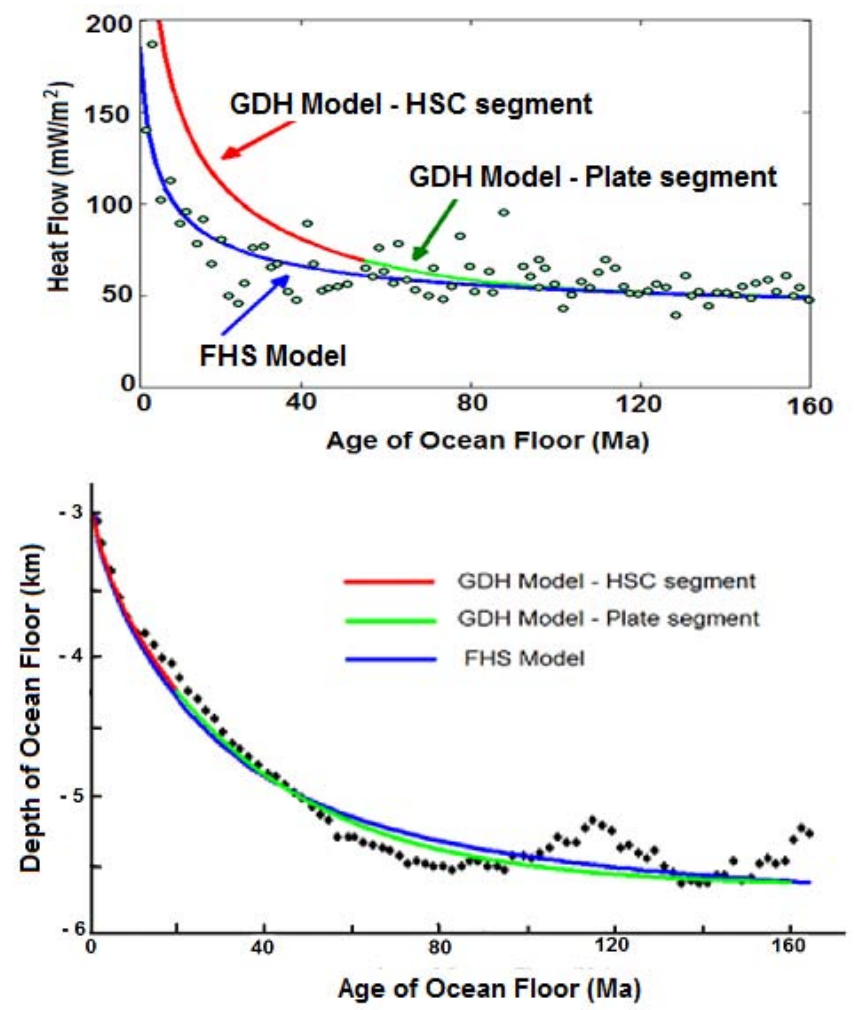

Fig. 3. Comparison of fits to observational heat flow (open circles in upper panel) and bathymetry data (closed circles in lower panel), by the global depth-heat flow (GDH) and finite half-space (FHS) models. The GDH model fit being a hybrid version is composed of two segments, derived from the half-space cooling (HSC) model (red curves) and plate model (green curves). The heat flow and bathymetry data are taken from Stein and Stein (1992).

The hard sedimentary layers may reach thicknesses of up to tens of kilometers, in several different tectonic settings. Nevertheless, hard sediment layers with thicknesses greater than five kilometers seem to be practically absent in Precambrian cratonic areas, unaffected by tectonic folding episodes. The crustal layers have thickness generally in the range of 30 to $40 \mathrm{~km}$ in the interior parts of the continents but may reach higher values in areas of collision tectonics.

The compilation reported in the work of Bassin et al. (2000) provides mean values of these parameters for a $2^{\circ} \times 2^{\circ}$ grid system. The available data sets have been used in calculating mean values of essential elements (thickness, density and seismic velocity) that characterize the crustal structure. These in turn have been employed in deriving maps of crustal thickness, an example of which is illustrated in Fig. 5.

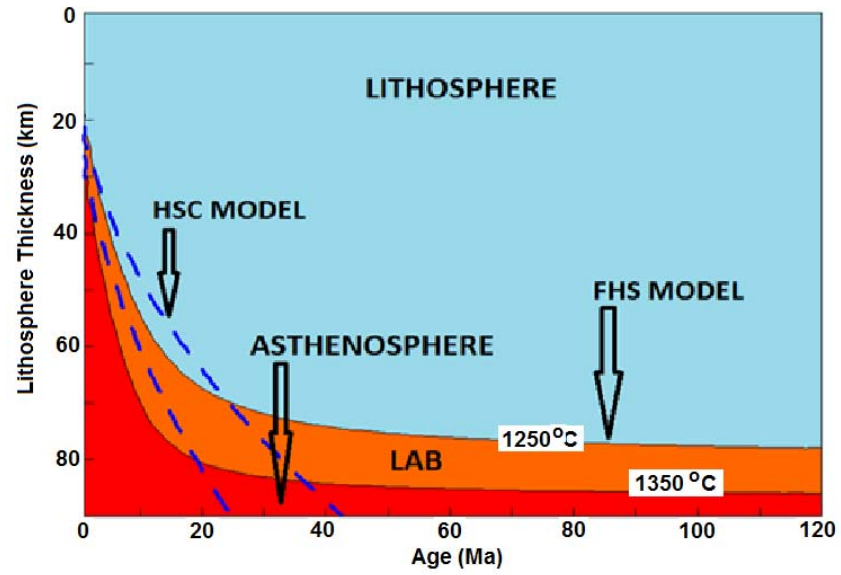

Fig. 4. Variations in the thickness of the oceanic lithosphere with age, according to the finite half-space (FHS) model, for the case of basal geotherms of $1250^{\circ} \mathrm{C}$ and $1350^{\circ} \mathrm{C}$. Also included here is a comparison of the variations in the thickness of the oceanic lithosphere with age, according to the finite half-space (FHS) and half-space cooling (HSC) models. The dashed curves in this figure indicate depths of LAB in the HSC model.

\subsection{Estimation of radiogenic heat in crustal layers}

Determination of radiogenic heat production is usually carried out by measuring the relative amounts of the main heat producing elements (uranium, thorium and potassium) in samples collected at the surface. In calculating the total contribution of radiogenic heat for the crustal layers it is necessary to determine not only the near surface values but also the vertical distribution of radiogenic heat with depth in the entire crust. Direct determination of heat production of crustal layers is a strenuous task because of the high degree of variability in the abundances of radioactive elements and the difficulties in obtaining representative samples from deeper layers of the crust.

Such difficulties in direct determination of radiogenic heat have been discussed in an earlier work by Smithson and Decker (1974). An alternative is to make use of empirical relations between seismic velocities and heat production. Rybach and Buntebarth (1984) proposed the following relation between seismic velocity $\left(V_{p}\right.$ in $\left.\mathrm{km} \mathrm{s}^{-1}\right)$ and heat production (A in $\mu \mathrm{Wm}^{-3}$ ):

$\ln (A)=B-2.17 V_{p}$.

The value of the parameter $B$ in Eq. (7) is 12.5 for Precambrian regions and 13.7 for Phanerozoic regions. Cermak and Bodri (1986) demonstrated the need to incorporate corrections for in-situ velocities. This procedure was employed by Cull (1991) for estimating total radiogenic heat production of the crust in Australia. 
Table 2. Mean radiogenic heat production values adopted in the present work for the system of layers constituting the structure of the lithosphere, based on compilations reported by Artemieva and Mooney (2001) and Jaupart and Mareschal (2004).

\begin{tabular}{llc}
\hline Layer & Crustal Layer/Classification & Heat Production $\left(10^{-6} \mathrm{~W} \mathrm{~m}^{3}\right)$ \\
\hline 1 & Soft Sediments & 1.0 \\
2 & Hard Sediments & 1.2 \\
3 & Felsic Upper Crust (Phanerozoic) & 2.3 \\
4 & Upper Crust (Archean) & 2.1 \\
5 & Intermediate Middle Crust & 1.4 \\
6 & Mafic Lower Crust & 0.5 \\
7 & Sub-crustal Lithosphere & 0.1 \\
\hline
\end{tabular}

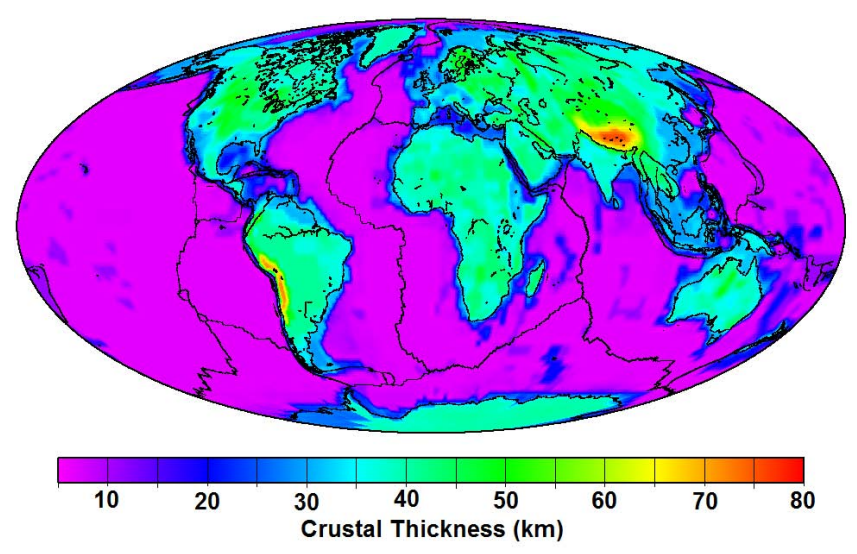

Fig. 5. Global distributions of the thickness of the continental crust, derived using the data base of Mooney et al. (1998).

The globally averaged values of heat production adopted for purposes of the present work are given in Table 2, for the five different crustal layers and the subcrustal lithosphere. In addition, a subdivision has been introduced in this table to allow for cases of Proterozoic and Archean segments of the upper crust. The global crustal model of Mooney et al. (1998) was employed in determining mean crustal thickness and mean velocity values for a regular grid system of $2^{\circ} \times 2^{\circ}$. Calculations carried out for this system of cells has allowed determination of regional variations of crustal heat production values in continental and oceanic regions. The results are employed in calculating the heat flux produced by radioactive elements in the crust. The map of Fig. 6 illustrates the global distribution of the radiogenic component of surface heat flux. As expected contribution of radiogenic heat production is significant mainly in areas of continental crust. Oceanic crust is practically free of any significant quantities of radiogenic heat.

\subsection{Thermal model of continental crust}

The thermal models of continental crust of the present work make use of relations that specify the vertical variations in thermal conductivity and radiogenic heat production. A sum-

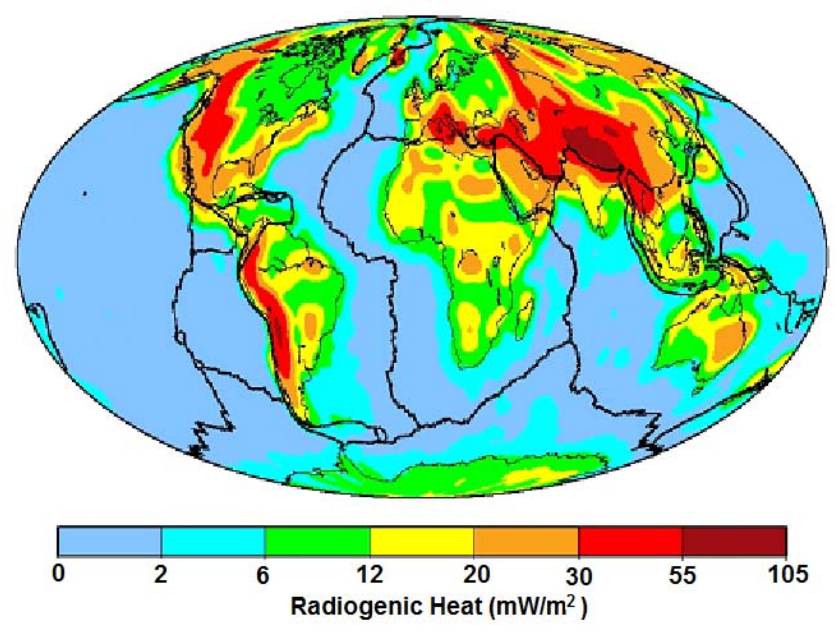

Fig. 6. Global map of heat flux produced by radiogenic elements in the Earth's crust, based on the crustal structure data set of Mooney et al., (1998) and the empirical relation between seismic velocity and heat production (Rybach and Buntebarth, 1984). Note the sharp contrast in heat production between continental and oceanic regions.

mary of the values of thermal conductivity adopted for the crustal layers as well as the relations used in specifying its variation with depth and temperature are provided in Table (3). Referring to this table, note that the relation for thermal conductivity of soft sediments (i.e. layer 1) allows for its variation with porosity, which in turn is depth dependent. On the other hand, the relation for hard sediments (i.e. layer 2) specifies that the effective value of thermal conductivity is determined by the vertical variations in compositional changes of lithologic sequences. In the case of upper crust (i.e. layers 3 and 4), the relation used allows for the observed trends of decrease in thermal conductivity with temperature. This decrease is due to phonon interactions in lattice structures of minerals at moderate values of temperatures. The thermal conductivity of middle crust (i.e. layer 5) has been assumed to be constant. This assumption is based on the argument that, at temperatures prevailing in the middle crust, the decrease in phonon component of thermal conductivity is 
likely to be compensated by the onset of the radiative component. On the other hand, the relation employed for layers 6 and 7 admits the possibility that radiative component of thermal conductivity is dominant in the lower crust and in the upper mantle.

The temperature in the continental lithosphere can be approximated by the steady state solution of the one dimensional heat conduction equation. For a medium with depth dependent thermal conductivity $(\lambda)$ and exponential decrease of heat production $(A)$ in the vertical direction $(z)$, the solution for temperature $(T)$ may be expressed as (Hamza, 1982)

$\left(\lambda_{0} / \alpha\right) \ln \left(u / u_{0}\right)=\left(q_{0}-A_{0} D\right) z+A_{0} D^{2}$

$\left[1-e^{-z / D}\right]$

where $u=1+\alpha T, \alpha$ being the temperature coefficient of thermal conductivity and $D$ is the logarithmic decrease in heat production with depth. The terms with subscripts zero $\left(\lambda_{0}, q_{0}\right.$ and $\left.A_{0}\right)$ represent values of the parameters (thermal conductivity, heat flux and radiogenic heat production, respectively) at the surface $(z=0)$.

Use of Eq. (6) is strictly valid only for shallow depth levels of the lithosphere where the phonon component of thermal conductivity decreases with temperature. At intermediate depths positive contribution of radiative component offsets the negative effects of the phonon component and effective values of thermal conductivity remains nearly the same. At larger depths thermal conductivity variations arising from radiative heat transfer become dominant. The complications arising from variations in thermal conductivity is likely to have only a limited impact on the final results of $\mathrm{LAB}$ estimates as most of the temperature variations occur in the upper parts of the lithosphere. Temperature variations in the deeper parts of continental lithosphere are relatively small and errors associated with variations in conductivity are likely to appear as relatively small systematic errors in the depth to LAB.

\subsection{Mantle heat flow}

The procedure outlined in the previous section has been employed in the present work for determining vertical variations in heat flux for the $2^{\circ} \times 2^{\circ}$ grid system. This work is greatly facilitated by updated global databases for heat flow (Vieira and Hamza, 2010) and crustal structure (Mooney et al., 1998). Heat flow values corrected for contributions of radiogenic heat were calculated at depths corresponding to the base of sedimentary strata, the upper crust and the lower crust. Note that the basal heat flux for the lower crust is the same as the mantle heat flux.

Equation (6) permits calculation of temperatures, constrained primarily by surface heat flow measurements and the vertical distribution of thermal parameters (thermal conductivity and heat production), within the crust and in the lithospheric mantle. It also allows determinations of vertical heat flux at any depth level in the crust. In other words, we have a means of implementing a back-stripping process for determining deep heat flux with progressive elimination of the contributions radiogenic heat in overlying layers. The results obtained in such a back-stripping process are illustrated in the set of maps of Fig. 7. The upper panel in this figure indicates global distribution of heat flow at the base of the sedimentary layer, which is nearly the same as surface heat flow. Note that near surface heat flow provides very few clues as to the contrasts in the deep thermal structures of continental and oceanic regions. The middle and lower panels of Fig. 7 refer respectively to the cases where the contributions of radiogenic heat of the upper and lower crust are removed by the back-stripping method. It is clear that progressive removal of the contributions of radiogenic heat of upper and lower crustal layers bring into evidence the differences in deep heat flux. A remarkable feature in the middle panel of Fig. 7 is the relatively narrow width of the transition zone of deep heat flux, between continental and oceanic regions. It is a clear indication that the heat producing sources are situated at shallow depths in the crust. Another outstanding feature, evident in the lower panel of this figure, is the contrast in the global distribution of mantle heat flux, which is less than $40 \mathrm{~mW} \mathrm{~m}^{-2}$ in most parts of the continental crust.

\section{Global distribution of depths to lithosphere- asthenosphere boundary (LAB)}

We now examine the global distribution of depths to LAB based on the results discussed in the previous Sects. 3 and 4. As in the case of oceanic regions, it is important to set a value for basal temperature that is compatible with studies of petrology and thermal models of the continental lithosphere. Again, there is no universal agreement as to the representative value of the basal temperature to be used in model studies of the continental lithosphere.

In continental regions estimates of basal temperatures of periods extending back to Archean times have been made based on analysis of mantle xenoliths. For example, $P-T$ conditions inferred for xenoliths from northern Lesotho is 1050 to $1250^{\circ} \mathrm{C}$ at depths of $170 \mathrm{~km}$ (O'Reilly and Griffin, 2006; Grütter et al., 2006). The xenolith data for the Slave Province in Canada reported by Kopylova et al. (1999) indicate that the conductive geotherm in the mantle extrapolates to the mantle adiabat with temperatures of $1350^{\circ} \mathrm{C}$ at depths of $200 \mathrm{~km}$. Though there are considerable uncertainties in the methodology it is fairly reasonable to conclude that the xenolith geotherms serve as upper limits for present day basal temperatures of the continental lithosphere. Thus, a mantle adiabat of $1300^{\circ} \mathrm{C}$ is considered as representative of the Precambrian cratons. However, as mantle convection depends on viscosity, which is itself temperature dependent, the base of the thermal lithosphere is sometimes defined as 0.85 times the solidus temperature. In this case basal temperatures would be somewhat lower, around $1100^{\circ} \mathrm{C}$ for a 
Table 3. Summary of the relations employed in specifying thermal conductivity $(\lambda)$ values for the system of layers constituting the structure of the lithosphere.

\begin{tabular}{clll}
\hline Layer & Crustal Layer/Classification & Relations for Thermal Conductivity & Reference \\
\hline 1 & $\begin{array}{l}\text { Soft } \\
\text { Sediments }\end{array}$ & $\begin{array}{l}\lambda_{\mathrm{SS}}=\lambda_{\mathrm{GR}}(1-\varphi)+\lambda_{\mathrm{PF}} \varphi \\
\varphi=\varphi_{0} \exp (-z / P)\end{array}$ & Woodside and Messmer (1961) \\
\hline 2 & $\begin{array}{l}\text { Hard } \\
\text { Sediments }\end{array}$ & $\lambda_{\mathrm{HS}}=1 /\left(\sum_{i=1}^{N} z_{i} R_{i} / \sum_{i=1}^{N} z_{i}\right)$ & Bullard (1939) \\
\hline 3 & Felsic Upper Crust (Phanerozoic) & $\lambda_{\mathrm{UC}}(T)=\lambda_{\mathrm{UC} 0} /(1+\alpha T)$ & Birch and Clarke (1940) \\
\hline 4 & $\begin{array}{l}\text { Upper Crust } \\
\text { (Archean) }\end{array}$ & $\lambda_{\mathrm{UC}}(T)=\lambda_{\mathrm{UC}} /(1+\alpha T)$ & Birch (1947) \\
\hline 5 & $\begin{array}{l}\text { Intermediate } \\
\text { Middle Crust }\end{array}$ & $\lambda_{\mathrm{MC}}($ Constant $)$ & Assumed \\
\hline 6 & $\begin{array}{l}\text { Mafic } \\
\text { Lower Crust }\end{array}$ & $\lambda_{\mathrm{LC}}(T)=\lambda_{\mathrm{LC} 0}(T / c)^{3}$ & Schatz and Simmons (1972) \\
\hline 7 & $\begin{array}{l}\text { Sub-crustal } \\
\text { Lithosphere }\end{array}$ & $\lambda_{\mathrm{UM}}(T)=\lambda_{\mathrm{UM} 0}(T / c)^{3}$ & Schatz and Simmons (1972) \\
\hline
\end{tabular}

The symbols used are:

$\lambda_{\mathrm{SS}}$ - Thermal conductivity of soft sediment layer; $\lambda_{\mathrm{GR}}-$ Thermal conductivity of solid grains in soft sediment layer;

$\lambda_{\mathrm{PF}}-$ Thermal conductivity of pore fluids in soft sediment layer; $\varphi$ - Porosity;

$\varphi_{0}$ - Porosity at depth $z=0 ; \mathrm{P}$ - Logarithmic decrement of porosity with depth;

$\lambda_{\mathrm{HS}}-$ Thermal conductivity of hard sediment layer; $\mathrm{R}_{i}$ - Thermal resistivity (inverse of thermal conductivity) of layer $\mathrm{i}$;

$\mathrm{N}$ Number of sedimentary layers; $\lambda_{\mathrm{UC}}-$ Thermal conductivity of upper crust;

$\lambda_{\mathrm{UC}}-$ Thermal conductivity of upper crust at $\mathrm{T}=T_{0} ; \alpha$-Temperature coefficient of thermal conductivity;

$\mathrm{T}$ - Absolute temperature; $\lambda_{\mathrm{MC}}-$ Thermal conductivity of middle crust;

$\lambda_{\mathrm{LC}}-$ Thermal conductivity of lower crust; $\lambda_{\mathrm{LC} 0}-$ Thermal conductivity of lower crust at temperature $T_{\mathrm{LC} 0}$;

$\lambda_{\mathrm{UM}}-$ Thermal conductivity of upper mantle; $\lambda_{\mathrm{UM} 0}-$ Thermal conductivity of upper mantle at temperature $T_{\mathrm{UM} 0}$.

mantle solidus of $1300^{\circ} \mathrm{C}$ (Pollack and Chapman, 1977). For purposes of the present work the basal temperature of lithosphere is assumed to fall in the interval of 1100 to $1300^{\circ} \mathrm{C}$.

As in the case of heat flow and radiogenic heat production data sets (discussed in Sects. 2 and 4 respectively) a regular grid system of $2^{\circ} \times 2^{\circ}$ cells was used in calculating mean values of depths to LAB. The data set generated in this procedure was used in deriving maps of the global distribution of LAB depths. One of the convenient forms of representing such gridded data sets is through the technique of spherical harmonic representation. The main limitation of this technique is the elimination of short wavelength variations resulting in loss of resolution. An alternative is to make use of the numerical interpolation schemes which may be coupled with automatic contouring techniques. The data sets that form the basis of these two approaches are included in the present work as Supplement. The maps of global distribution of LAB depths derived from the data sets in the supplementary files are presented in the two panels of Fig. 8. In this figure, the upper panel refers to the map produced by spherical harmonic representation while the lower panel refers to the map by numerical interpolation. The maps obtained in both types of representations reveal that LAB depths are less than $50 \mathrm{~km}$ in areas of sea floor spreading. Examples are the approximately north-south trending mid-ocean ridge systems in the Atlantic, Pacific and Indian Ocean areas. Other regions of relatively thin lithosphere are the back-arc regions associated with subduction zones. In continental regions Cenozoic rift zones and areas of recent magmatic activity stand out as areas of shallow LAB.

On the other hand, the interior parts of continental regions are characterized by thick lithosphere. The Archean cratons with relatively thick lithospheric roots include Siberian Platform, West Africa, Baltic Shield, South Africa, Western Australia, the Indian Shield, Cathaysian Craton, and the San Francisco Craton in South America (Jordan, 1975; Eaton et al, 2009; Fischer et al, 2010). There are some indications of progressive thickening of the lithosphere in areas of cratonic nuclei.

\section{Discussion and conclusions}

The present work has allowed derivation of new global maps of the depth to the boundary between the lithosphere and the asthenosphere. The maps are based on updated global databases for heat flow (Vieira and Hamza, 2010) and crustal structure (Mooney et al., 1998). For continental regions the estimates of lithospheric thickness are based on determinations of subcrustal heat flow, after corrections for contributions of radiogenic heat in crustal layers. For oceanic regions 


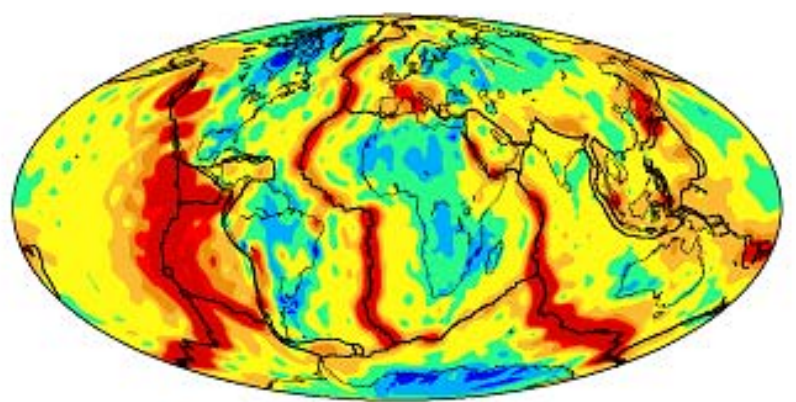

Surface Heat Flux

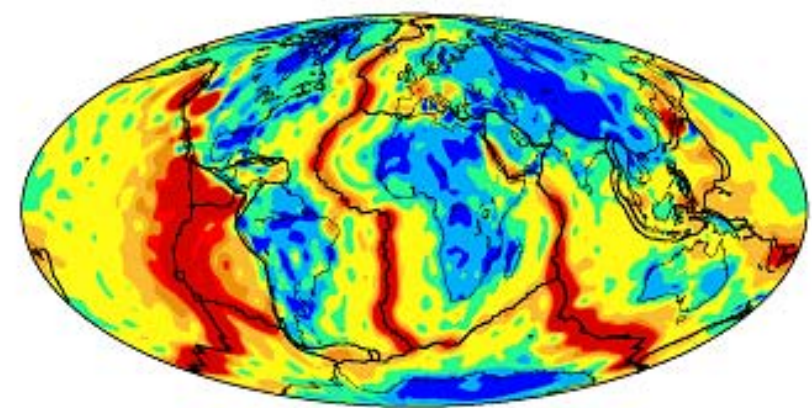

Lower Crustal Heat Flux

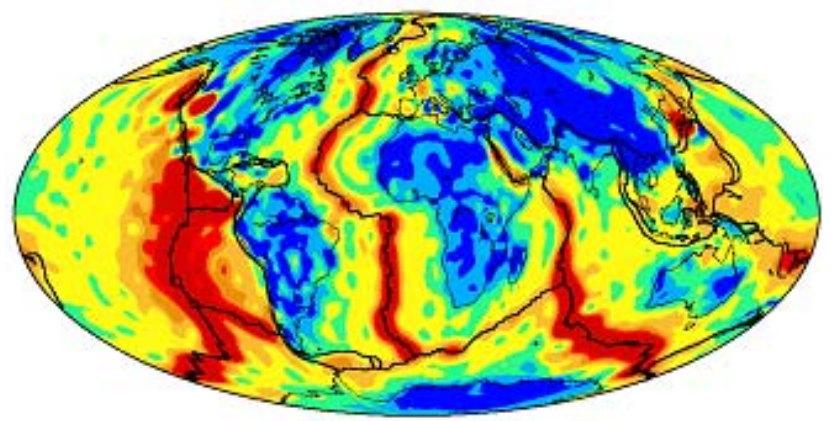

Mantle Heat Flux

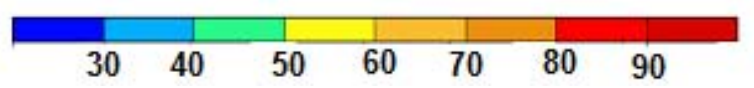

Fig. 7. Heat flow corrected for contributions of radiogenic heat at the base of sedimentary layers (upper panel), base of upper crust (middle panel) and base of lower crust (lower panel). Note that near surface heat flow (upper panel) provides very few clues as to the contrasts in the deep thermal structures of continental and oceanic regions. As the contributions of radiogenic heat of upper and lower crustal layers progressively remove the differences in deep heat flux between these regions becomes evident (middle and lower panels).

the estimates of lithospheric thickness are based on the newly proposed finite half-space (FHS) model. Results of numerical simulations reveal that theoretical values derived from FHS model provide vastly improved fits to observational data for heat flow and bathymetry than can be achieved with HSC and plate models. Hence, estimates of depths to lithosphere-

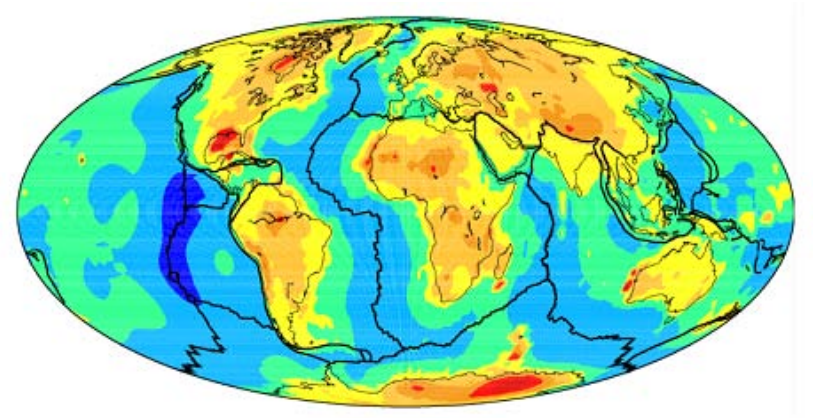

Depth to LAB - Spherical Harmonic Representation

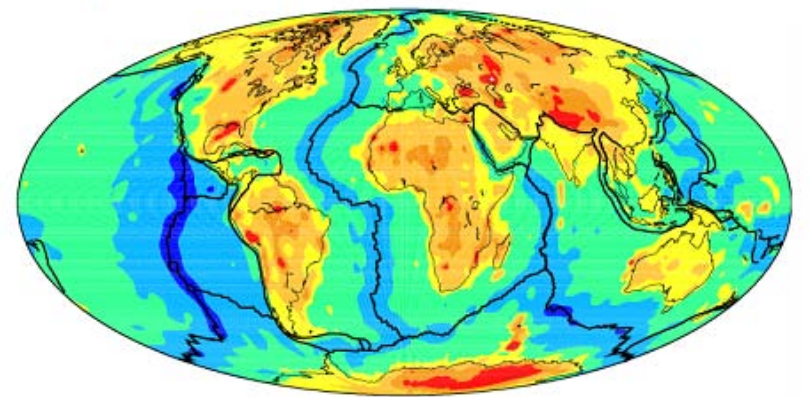

Depth to LAB - Numerical Interpolation

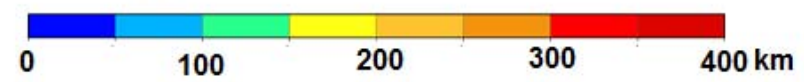

Fig. 8. Global distributions of depth to LAB in spherical harmonic representation (upper panel) and numerical interpolation methods (lower panel). Note that almost all of the continental areas are characterized by lithospheric thickness greater than $150 \mathrm{~km}$.

asthenosphere boundary (LAB) based on FHS model are believed to provide more reliable estimates than those reported in previous thermal models.

The global maps of depths to LAB derived in the present work reveal several features in regional variations of lithosphere thicknesses that have not been identified in earlier studies. For example, regions of ocean floor with ages less than $55 \mathrm{Ma}$ are characterized by relatively rapid thickening of the lithosphere. Also there is better resolution in mapping the transition from oceanic to continental lithosphere, as most of the latter ones are characterized by lithospheric thickness greater than $150 \mathrm{~km}$. As expected the plate spreading centers in oceanic regions as well as areas of recent magmatic activity in continental regions are characterized by relatively thin lithosphere, with LAB depths of less than $50 \mathrm{~km}$. Almost all of the continental areas are characterized by lithospheric thickness greater than $150 \mathrm{~km}$. Regional variations of lithosphere thickness in the interiors of continents are found to depend on the magnitude of sub-crustal heat flux as well as the tectonic age of crustal blocks. Areas of continental collisions and Precambrian cratonic blocks are found to have lithosphere thicknesses in excess of $250 \mathrm{~km}$. 
Another major conclusion arising from results of the present work is that the processes which play dominant roles in controlling LAB depths in oceanic regions are distinctly different from those that operate in continental regions. For example, magma accretion at the base of the lithosphere plays a major role in determining depths of LAB in oceanic regions. Rapid decrease in magma accretion is believed to be the mechanism for the accentuated increase in thickness of the lithosphere with distance from the ridge axis. This implies that variations in depths of LAB are strongly related to the age of the ocean crust. On the other hand, LAB depths in continental regions seem to be determined to a large extent by the thermal structure of crustal blocks at the top boundary. The role of basal magma accretion is much less subdued in continental regions. This conclusion is different from the proposal of Artemieva and Mooney (2002) that basal drag is a possible mechanism that may account for variations in depths of continental LAB. Nevertheless, the results obtained in the present work are in general agreement with those of seismic and magnetotelluric studies (Praus et al, 1990). Results of deep seismic soundings reveal that the base of the seismic lithosphere is diffuse. But the general conclusion that Achaean cratons have relatively thick lithospheric roots is in agreement with results of the present work (Plomerová et al, 2008; Plomerová and Babuska, 2010).

\section{Supplementary material related to this article is available online at: http://www.solid-earth.net/3/199/ 2012/se-3-199-2012-supplement..pdf.}

Acknowledgements. This work was carried out as part of research project with funding from Conselho Nacional de Desenvolvimento Científico - CNPq (Project No. 301865/2008-6; Produtividade de Pesquisa - PQ). Thanks are due to Andres Papa (ON- ObservatórioNacional) for institutional support.

Special Issue: "The Lithosphere-Asthenosphere Boundary (LAB) Dilemma"

Edited by: U. Achauer, J. Plomerova, and R. Kind

\section{References}

Artemieva, I. M.: Global $1^{\circ} \times 1^{\circ}$ thermal model TC 1 for the continental lithosphere: Implications for lithosphere secular evolution, Tectonophysics, 416, 245-277, 2006.

Artemieva, I. M. and Mooney, W. D.: Thermal thickness and evolution of Precambrian lithosphere: A global study, J. Geophys. Res., 106, 16387-16414, 2001.

Artemieva, I. M. and Mooney, W. D.: On the relations between cratonic lithosphere thickness, plate motions, and basal drag, Tectonophysics, 358, 211-231, 2002.

Babuška, V. and Plomerová, J., European mantle lithosphere assembled from rigid microplates with inherited seismic anisotropy, Phys. Earth Planet. In., 158, 264-280, 2006.
Bassin, C., Laske, G., and Masters, G.: The current limits of resolution for surface wave tomography in North America. EOS Trans, AGU 81, 897, 2000.

Birch, F. and Clark, H., The thermal conductivity of rocks and its dependence upon temperature and composition, Am. J. Sci., 238, 529-558, 1940.

Bullard, E. C.: Heat flow in South Africa, P. R. Soc. Lond., 173, 474-502, 1939.

Cardoso R. R. and Hamza V. M.: Crustal heat flow variations of in the Equatorial Atlantic: implications for geothermal structure of NE Brazil, in: Proceedings of the 2nd symposium of the Brazilian Geophysical Society, Natal, 6 pp, 2006.

Cardoso, R. R. and Hamza, V. M.: A Simple conduction advection model of the lithosphere and possible demise of the hypothesis of regional hydrothermal circulation in the ocean crust,in: Proceedings of the 10th Int. Congress of the Brazilian Geophys. Society, Rio de Janeiro, Brazil, 2007.

Cardoso, R. R. and Hamza, V. M.: Finite Half-Space Model of Oceanic Lithosphere., in: Horizons in Earth Science Research, edited by: Veress, B. and Szigethy, J., 11, 375-395, 2011.

Carslaw, H. S. and Jaeger, J. C.: Conduction of Heat in Solids, Oxford University Press, New York, NY, USA, 2 Edn, 1959.

Cermak, V. and Bodri, L.: A heat production model of the crust and upper mantle. Tectonophysics, 194, 307-323, 1991.

Conrad, C. P. and Lithgow-Bertelloni, C.: Influence of continental roots and asthenosphere on plate-mantle coupling. Geophy. Res. Lett., 33, doi:10.1029/2005GL025621, 2006.

Cull, J. P.: Heat Flow and Regional Geophysics in Australia. In Terrestrial Heat Flow and the Lithosphere Structure, edited by: Cermak, V. and Rybach, L., Springer, New York, 486-500, 1991.

Davies, J. H. and Davies, D. R.: Earth's surface heat flux, Solid Earth, 1, 5-24, doi:10.5194/se-1-5-2010, 2010.

Eaton, D. W., Darbyshire, F., Evans, R. L., Grütter, H., Jones, A. G., and Yuan, X., The elusive lithosphere-asthenosphere boundary (LAB) beneath cratons, Lithos, 109, 1-22, 2009.

Fischer, K. M., Ford, H. A., Abt, D. L. and Rychert, C. A., The Lithosphere-Asthenosphere Boundary, Annu. Rev. Earth Planet. Sci., 38, 551-575, 2010.

Green, D. H., Falloon, T. J., Eggins, S. M. and Yaxley, G. M., Primary magmas and mantle temperatures, Eur. J. Mineral., 2001, 13, 437-451, 2001.

Grütter, H., Latti, D., and Menzies, A.: Cr-saturation arrays in concentrate garnet compositions from Kimberlite and their use in mantle barometry, J. Petrol. 47, 801-820, 2006.

Hamza, V. M.: The relationship of heat flow with geologic age. Internal Report, Nat. Geophys. Res. Ins., Hyderabad (India), 1967.

Hamza, V. M.: Thermal Structure of South American Continental Lithosphere during Archean and Proterozoic. Rev. Bras. Geociências, 149-159, 1982.

Hamza, V. M. and Verma, R. K.: Relationship of heat flow with the age of basement rocks, Bull. Volcan., 33, 123-152, 1969,

Hamza, V. M., Cardoso, R. R. and Ponte Neto, C. F.: Global Heat flow: Fantasy and Facts (Abstract), Sixth International Meeting Heat Flow and the Structure of the Lithosphere, Bykov (Czech Republic), 47, 2006.

Hamza, V. M., Cardoso, R. R., and Ponte Neto, C. F., Spherical Harmonic Analysis of Earth's Conductive Heat Flow, Int. J. Earth Sci., 97, 205-226, 2008a. 
Hamza, V. M., Cardoso, R. R., and Ponte Neto, C. F.: Reply to Comments by Henry N. Pollack and David S. Chapman on "Spherical Harmonic Analysis of Earth's Conductive Heat Flow". Int. J. Earth Sci., 97, 233-239, 2008b.

Hamza, V. M., Cardoso, R. R., and Alexandrino, C. H.: A Magma Accretion Model for the Formation of Oceanic Lithosphere: Implications for Global Heat Loss, Int. J. Geophys., 16, doi:10.1155/2010/146496, 2010.

Hofmeister A. M. and Criss R. E., Earth's heat flux revised and linked to chemistry, Tectonophysics, 395, 159-177, 2005.

Iyer, S. S., Babinski, M., and Hamza, V. M., Radiogenic heat production in sedimentary rocks of the Bambui Group: Implications for thermal history and hydrocarbon generation, Proceedings Brazilian Geological Congress, Salvador (BA), 6, 521-523, 1996.

Jaupart, C. and Mareschal, J. C., The thermal structure and thickness of continental roots, Lithos, 48, 93-114, 1999.

Jaupart, C. and Mareschal, J. C., Constraints on crustal heat production from heat flow data, in: Treatise on Geochemistry, Elsevier, edited by: Rudnick, R. L., 3, 65-84, 2004.

Jordan, T. H., The continental tectosphere, Reviews of Geophysics and Space Physics, 13, 1-12, 1975.

Jordan, T. H., Continents as a chemical boundary layer, Philos. T. R. Soc. Lond., 301, 359-373, 1981.

Kopylova, M. G., Russell, J. K., and Cookenboo, H.: Petrology of Peridotite and Pyroxenite xenoliths from the Jericho Kimberlite: implications for the thermal state of the mantle beneath the Slave Craton, Northern Canada, J. Petrol., 40, 79-104, 1999.

Kusznir, N. and Karner, G., Dependence of the flexural rigidity of the continental lithosphere on rheology and temperature, Nature, 316, 138-142, 1985.

McKenzie, D. P., Some remarks on heat flow and gravity anomalies, J. Geophys. Res., 72, 6261-6273, 1967.

McKenzie, D. and Bickle, M. J.: The volume and composition of melt generated by extension of the lithosphere, J. Petrol., 29, 625-679, 1988.

McKenzie, D., Jackson, J., and Priestley, K., Thermal structure of oceanic and continental lithosphere, Earth Planet. Sci. Lett., 233, 337-349, 2005.

McNutt, M.: Flexure reveals great depth, Nature, 343, 205-260. 1990 ,

Mooney, W. D., Laske, G., and Masters, T. G.: CRUST 5.1: A global crustal model at 5 x 5 J. Geophys. Res., 103, 727-747, 1998.

Muller, R. D., Roest, W. R., Royer, J., Gahagan, L. M. and Sclater, J. G., Digital isochrons of the world's ocean floor. J. Geophys. Res., 102, 3211-3214, 1997.

Nabelek, P. I., Whittington, A. G., and Hofmeister A. M.: Strain heating as a mechanism for partial melting and ultrahigh temperature metamorphism in convergent orogens: Implications of temperature-dependent thermal diffusivity and rheology, J. Geophys. Res., 115, B12417, doi:10.1029/2010JB007727, 2010.

O'Reilly, S. Y. and Griffin, W. L.: Imaging global chemical and thermal heterogeneity in the sub continental lithospheric mantle with garnets and xenoliths: geophysical implications, Tectonophysics, 416, 289-309, 2006.

Ozisik, M. N.: Heat Conduction, John Wiley and Sons, New York, NY, USA, 1980.
Parsons, B. and Sclater, J. G.: An Analysis of the variation of ocean floor bathymetry and heat flow with age, J. Geophys. Res., 82, 803-827, 1977.

Plomerová, J. and Babuška, V., Long memory of mantle lithosphere fabric - European LAB constrained from seismic anisotropy, Lithos, 120, 131-143, 2010.

Plomerová, J., Babuška, V., Kozlovskaya, E., Vecsey, L., and Hyvönen, L. T., Seismic anisotropy - A key to resolve fabrics of mantle lithosphere of Fennoscandia, Tectonophysics, 462, 125136, 2008.

Plomerová, J., Babuška, V., Vecsey, L., Kozlovskaya, E., and Raita, T., Proterozoic-Archean boundary in the mantle lithosphere of eastern Fennoscandia as seen by seismic anisotropy, J. Geodynamics, 41, 400-410, 2006.

Pollack, H. N. and Chapman, D. S.: On the regional variation of heat flow, geotherms, and lithospheric thickness, Tectonophysics, 38, 279-296, 1977.

Pollack, H. N., Hurter, S. J., and Johnson, J. R.: Heat flow from the Earth's interior: Analysis of the global data set, Rev. Geophys., 31, 267-280, 1993.

Polyak, B. G. and Smirnov, Ya, B.: Relationship between terrestrial heat flow and tectonics of continents, Geotectonics 4, 205-213, 1968 (in Engish).

Praus, O., Pecova, J., Petr, V., Babuska, V., and Plomerova, J.: Magnetotelluric and seismological determination of the lithosphereasthenosphere transition in central Europe, Phys. Earth Planet. In., 60, 212-228, 1990.

Rybach, L. and Buntebarth, G.: The variation of heat generation, density and seismic velocity with rock type in the continental lithosphere, in: Terrestrial Heat Flow Studies and the Structure of the Lithosphere, edited by: Cermak, V., Rybach, L., and Chapman, D. S., Tectonophysics, 103, 335-344, 1984.

Schatz, J. and Simmons G.: Thermal conductivity of earth materials at high temperatures, J. Geophys. Res., 77, 6966-6983, 1972.

Sclater, J. G. and Francheteau, J.: The implications of terrestrial heat flow observations on current tectonic and geochemical models of the crust and upper mantle of the Earth, Geophys. J. Roy. Astr. Soc., 20, 509-542, 1970.

Sclater, J. G., Lawyer, L. A., and Parsons, B.: Comparison of LongWavelength Residual Elevation and Free-Air Gravity Anomalies in the North Atlantic and Possible Implications for the Thickness of the Lithospheric Plate, J. Geophys. Res., 80, 1031-1052, 1975.

Sclater, J. G., Jaupart, C., and Galson, D.: The heat flow through oceanic and continental crust and the heat loss of the Earth, Rev. Geophys., 18, 269-311, 1980.

Shapiro, S. S., Hager, B. H., and Jordan, T. H.: The continental tectosphere and Earth's long-wavelength gravity field, Lithos, 48, 135-152, 1999.

Smithson, S. B. and Decker, E. R.: A continental crustal model and its geothermal implications. Earth Planet, Sci. Lett., 22, 215-225, 1974.

Stein, C. and Stein, S.: A model for the global variation in oceanic depth and heat flow with lithospheric age, Nature, 359, 123-129, 1992.

Turcotte, D. L. and Oxburgh, E. R., Finite amplitude convective cells and continental drift, The J. Fluid Mechanics, 28, 29-42, 1967. 
Vieira, F. P. and Hamza, V. M.: Global Heat Loss: New Estimates Using Digital Geophysical Maps and GIS Techniques., Proceedings of the IV Symposium of the Brazilian Geophysical Society, 14-17 November, 2010, 1-6, 2010.
Whittington, A. G., Hofmeister, A. M., and Nabelek, P. I.: Temperature dependent thermal diffusivity of Earth's crust: Implications for crustal anatexis, Nature, 458, 319-321, 2009.

Woodside, W. and Messmer, J. H.: Thermal conductivity of porous media, I: Unconsolidated sands, II. Consolidated rocks, J. Appl. Phys., 32, 1688-1706, 1961. 